\title{
Identification of Secreted Virulence Factors of Chromobacterium violaceum ${ }^{\S}$
}

\author{
Thiago Castro-Gomes ${ }^{1}$, Mariana S. Cardoso ${ }^{1}$, \\ Wanderson D. DaRocha ${ }^{3}$, Letícia A. Laibida ${ }^{3}$, \\ Andréa M. A. Nascimento ${ }^{2}$, \\ Luciana W. Zuccherato', \\ Maria Fátima Horta ${ }^{1}$, Marcelo P. Bemquerer ${ }^{4}$, \\ and Santuza M. R. Teixeira ${ }^{1 \star}$ \\ ${ }^{1}$ Departamento de Bioquímica e Imunologia and ${ }^{2}$ Departamento de \\ Biologia Geral, Universidade Federal de Minas Gerais, Belo Horizonte, \\ MG, Brazil \\ ${ }^{3}$ Departamento de Bioquímica e Biologia Molecular, Universidade \\ Federal do Paraná, Curitiba, PR, Brazil \\ ${ }^{4} E M B R A P A$ Recursos Genéticos e Biotecnologia, Brasília, DF, Brazil \\ (Received Apr 5, 2013 / Revised Aug 1, 2013 / Accepted Aug 8, 2013)
}

Chromobacterium violaceum, a component of tropical soil microbiota, is an opportunistic pathogenic bacterium that can infect humans and other animals. In addition to identifying a large number of genes that demonstrate the vast biotechnological potential of this bacterium, genome sequencing revealed several virulence factors, including different $c y-$ tolysins, which can be related to its pathogenicity. Here we confirmed these predictions from genomic analyses by identifying, through mass spectrometry, proteins present in the culture supernatant of $C$. violaceum that may constitute secreted virulence factors. Among them, we identified a secreted collagenase and the product of a gene with sequence similarity to previously characterized bacterial porins.

Keywords: Chromobacterium violaceum, genome, hemolysin, virulence factor

Chromobacterium violaceum is a Gram-negative $\beta$-proteobacterium that inhabits a variety of ecosystems such as water and soil of tropical and subtropical regions (Durán and Menck, 2001). The most striking feature of $C$. violaceum is its, purple-colored pigment derived from tryptophan, known as violacein, a bacterial secondary metabolite that has antioxidant and antimicrobial activities (Hoshino, 2011). C. violaceum is also recognized as an opportunistic pathogen that

\footnotetext{
*For correspondence. E-mail: santuzat@icb.ufmg.br; Tel.: +55-31-34092665

SSupplemental material for this article may be found at

http://www.springerlink.com/content/120956.
}

can infect humans and other animals. Although rare, infections with this bacterium are characterized by rapid dissemination and high mortality rates (Chattopadhyay et al., 2002; Brito et al., 2004).

The sequence of the C. violaceum genome revealed numerous genes related to the biotechnological and pharmaceutical potential of this extremely versatile bacterium (Vasconcelos et al., 2003). Moreover, the identification of pathogenicity islands harboring genes encoding virulence factors shows that $C$. violaceum has a genetic background also compatible with a potentially pathogenic bacterium (Vasconcelos et al., 2003; Brito et al., 2004). In addition to the twelve open reading frames (ORFs) previously described in the original genome analysis of $C$. violaceum as sequences encoding hemolysin-like proteins, we have identified another seven genes, five of them encoding proteins with sequence homology to porins from Gram-negative bacteria (Supplementary data Table S1). Among a total of nineteen C. violaceum genes that can be considered potential virulence factors, there are members of the $h l y C A B D$ operon found in uropathogenic Escherichia coli and in various Gram-negative bacteria, which includes a gene encoding a calcium binding hemolysin, $h l y A$, containing the RTX (repeat-in-toxin) motif (CV0516) as well as components of the type I transport apparatus present in the inner membrane of various pathogenic bacteria (CV0513 and CV0514). Two other genes encoding hemolysins were also found associated with activator/transporter proteins: CV1918, whose product has been characterized as a Serratialike hemolysin (Brumbach et al., 2007) and is linked to a gene (CV1917) encoding an outer membrane protein that activates and secretes the cytolysin. Similarly, CV2872 encodes a large protein homologous to hemolysin-type calciumbinding proteins and is adjacent to a gene encoding a hemolysin activator protein (CV2873). Two genes encoding proteins with high similarity to hemolysins that have lipolytic activity (CV0360 and CV0362) were also found next to each other. Interestingly, a gene encoding a protein similar to sphingomyelinases from several bacteria, including Pseudomonas aeruginosa and the $\beta$-hemolysin of Staphylococcus aureus (CV3275) was found in the operon that encodes components of the violacein biosynthetic pathway. Lastly, five genes (CV1646, CV1989, CV3104, CV3424, and CV3829) showing sequence homology to porins from Gram-negative bacteria, as well as genes encoding a hemolysin III family channel protein (CV3342), a hemolysin A (CV4301) and two other putative hemolysin genes (CV0231 and CV0656), are sequences encoding potentially membrane-damaging pro- 
(A)

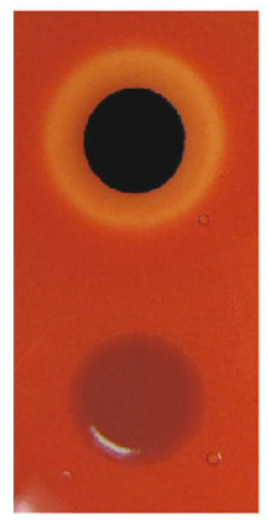

(B)

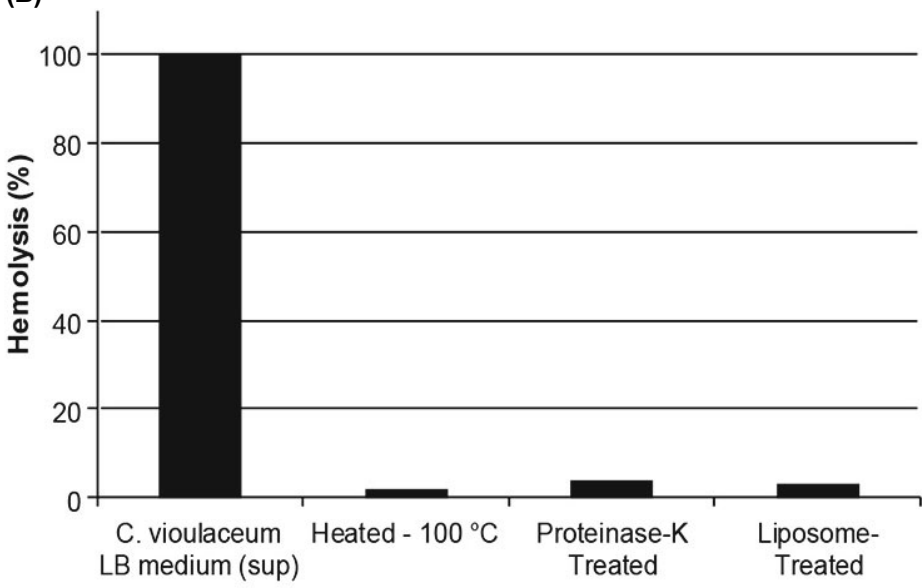

(C)

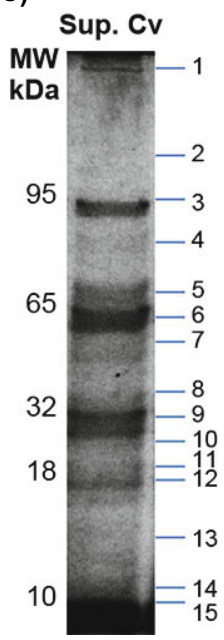

Fig. 1. Secreted hemolytic activity in cultures of $C$. violaceum. (A) Hemolytic activity of C. violaceum detected in LB-blood agar plates. C. violaceum ATCC 12472 (upper colony) or E. coli XL-1 blue strain (bottom colony) inoculated into blood agar plates were incubated at $37^{\circ} \mathrm{C}$ for 24 h. (B) Hemolytic activity in the culture supernatant of $C$. violaceum. Where indicated, the inactivation of hemolytic activity by heating and proteinase-K treatments or its removal from the culture supernatant by incubation with DPPC unilamellar liposomes is shown. (C) Proteins present in the supernatant of C. violaceum cultures. After fractionation by SDS-PAGE, the gel containing secreted C. violaceum proteins was sliced into fifteen fractions. Each fraction was treated with trypsin and then proteins were identified by mass spectrometry, as shown in Table 1.

teins also present in the C. violaceum genome. Taken together, these sequences indicate that, in addition to the hemolysin described by Brumbach et al. (2007), C. violaceum has the potential of producing a diverse group of cytolytic toxins that may act together to determine its pathogenic capacity.

Hemolytic activity, a well-known virulence factor produced by a variety of pathogenic bacteria, has been detected in clinical isolates as well as in soil isolates of C. violaceum (Miller et al., 1988). Recently, C. haemolyticum, a novel species within the genus Chromobacterium, was characterized as a strongly hemolytic bacterium (Han et al., 2008; Lima-Bittencourt et al., 2011). Here, we have confirmed that the hemolytic activity previously described in some C. violaceum isolates (Miller et al., 1988) is present in the ATCC12472 strain (which had its genome sequenced and was isolated from freshwater in Malaysia) and have also shown that this activity is due to a secreted protein. In contrast to a non-hemolytic E. coli colony, a clear zone of hemolysis around $C$. violaceum colonies grown on agar plates containing $5 \%$ human red blood cells showed its ability to secrete a hemolytic factor (Fig. 1A). To confirm its proteinaceous nature, culture supernatants of $C$. violaceum was assayed after several treatments including protease digestion. Following the method described by Andrews and Whitlow (1988), $20 \mu$ of bacterial supernatant from stationary phase cultures of C. violaceum were incubated with $5 \times 10^{6}$ red blood cells in $200 \mu \mathrm{l}$ of PBS, pH 6.5 at $37^{\circ} \mathrm{C}$ for $2 \mathrm{~h}$ and lysis was quantified by measuring hemoglobin in the supernatant at $414 \mathrm{~nm}$. The hemolytic activity detected in the $C$. violaceum supernatant was affected when the supernatant was pre-treated with $200 \mu \mathrm{g} / \mathrm{ml}$ of proteinase-K, heating at $100^{\circ} \mathrm{C}$ or incubation with 1,2-dipalmitoylphosphatidylcholine (DPPC) liposomes (Fig. 1B). All these treatments resulted in complete inactivation of the hemolytic activity present in the supernatant, indicating the proteic nature of this secreted hemolysin and its capacity to interact with a lipid bilayer. When we analyzed the protein profile of the C. violaceum culture supernatant we found a large number of proteins with molecular masses varying from 10 to more than $100 \mathrm{kDa}$ (Fig. 1C).

Next, to determine the identity of this hemolytic factor as well as to search for other potential virulence factors secreted by $C$. violaceum, we used mass spectrometry (MS) to analyze proteins present in the C. violaceum culture supernatant. Samples were first separated in 10\% SDS-PAGE (Fig. 1C) and 15 gel slices were prepared for MS analysis according to the protocols described in the supplementary data material. As shown in Table 1 we were able to identify six gene products for which we obtained a complete match of the peptide sequences. This table also shows the molecular weight for each protein, which, in most cases, is compatible with the predicted molecular weight based on the genome sequence. All mass spectra and peptide sequences are shown as Supplementary data Fig. S1. It is noteworthy that the product of the C. violaceum CV3424 gene, previously identified by in silico analysis of the $C$. violaceum genome as a porin, belonging to the family of outer membrane proteins (OmpC) (Nikaido, 2003; Rolhion et al., 2005), was unambiguously identified from the alignment of four MS/MS peptides (Table 1 ), suggesting that this protein might be one of the factors responsible for the $C$. violaceum-secreted lytic activity. A blast search analysis with the CV3424 sequence also identified four additional genes in the $C$. violaceum genome that show sequence similarity to OmpC from Neisseria meningitidis (see in Supplementary data Fig. S2 an alignment of these sequences). Besides being a component of the bacterial outer membranes, OmpC is found in culture supernatants of different bacteria and has been described as being associated with the invasion capacity of pathogenic strains of $E$. coli (Rolhion et al., 2005). A role of OmpC proteins as viru- 


\begin{tabular}{|c|c|c|c|c|}
\hline $\begin{array}{c}\text { SDS-PAGE } \\
\text { Sample Number }\end{array}$ & MW (kDa) & Tryptic peptide sequences & $\begin{array}{l}\text { C. violaceum gene } \\
\text { (Accession number) }\end{array}$ & Gene description \\
\hline 3 & 95 & $\begin{array}{l}\text { DGTFYTFQR } \\
\text { LFQADSFSYR } \\
\text { ESYLTLEELVR } \\
\text { QSVAETLILADSVR }\end{array}$ & $\begin{array}{c}\text { CV2001 } \\
\text { (AAQ59673) }\end{array}$ & Microbial collagenase \\
\hline 6 & 65 & $\begin{array}{l}\text { FQTTDYFKPTR } \\
\text { EFNADDVAFTFDR } \\
\text { VDNLVFAITTDPSVR } \\
\text { WDVAADGLSYTFHL }\end{array}$ & $\begin{array}{c}\text { CV1097 } \\
\text { (AAQ58772) }\end{array}$ & $\begin{array}{l}\text { Protein component of } \mathrm{ABC} \\
\text { transporter }\end{array}$ \\
\hline 9 & 32 & $\begin{array}{l}\text { TAMQAEFDQLGK } \\
\text { LDHVINNLSNVNNNTLAAK }\end{array}$ & $\begin{array}{c}\text { CV3011 } \\
(\text { AAQ60680) }\end{array}$ & Flagelin D \\
\hline 11 & 18 & $\begin{array}{l}\text { NSFIGLQGGFGTVR } \\
\text { GGADVAGQDWFDLVK } \\
\text { LDNTQYDQYVLGADYAISK } \\
\text { TIWQVETGFAIDGNKDQYSK }\end{array}$ & $\begin{array}{c}\text { CV3424 } \\
\text { (AAQ61087) }\end{array}$ & Porin \\
\hline 14 & 10 & $\begin{array}{l}\text { QAPFFAGEK } \\
\text { AYDVEADGGVAFR } \\
\text { SGVVQHQVVNNLPLGR } \\
\text { NVEVIGVSIDSQFTHAAW }\end{array}$ & $\begin{array}{c}\text { CV3739 } \\
(\text { AAQ61401) }\end{array}$ & Peroxidase \\
\hline 15 & $<10$ & $\begin{array}{l}\text { VNHGVYEITHFLDK } \\
\text { LEQPAQASASTAGGATAER } \\
\text { IDGIPGESDDKHKDWIEIQSFSHK }\end{array}$ & $\begin{array}{c}\text { CV3977 } \\
\text { (AAQ61639) }\end{array}$ & $\begin{array}{l}\text { Hemolysin co-regulated protein } \\
\text { (Hcp) }\end{array}$ \\
\hline
\end{tabular}

lence factors is also supported from studies of Shigella flexneri $\triangle o m p C$ mutants, which have their host cell killing capacity as well as their ability to spread from one epithelial cell to another severely affected (Bernardini et al., 1993). Similarly, Salmonella typhimurium mutants deficient in both OmpC and $\mathrm{OmpF}$ have attenuated virulence in vivo (Chatfield et al., 1991). Analyses based on prediction of protein secretion indicate that all five $C$. violaceum genes containing sequences with similarity to OmpC porins encode secreted proteins. As discussed by Cluss et al. (2004), secretion of the outer membrane porin Oms 28 by Borrelia burgdorferi is associated with the release of outer membrane vesicles (OMV) but also occurs by a vesicle-independent mechanism. Whether the C. violaceum OmpC porin is released as components of OMVs, remains to be determined. It also remains to be determined whether, in addition to CV3424, other $C$. violaceum porins are expressed and secreted in the supernatant under the culture conditions we used or if the expression of each one of these genes is dependent on different culture conditions.

The second protein identified in the C. violaceum supernatant as potentially involved with its cytolytic activity is encoded by the CV3977 gene (annotated as encoding a hypothetical protein in the C. violaceum genome database) and shares the DUF796 domain present in members of the Hcpl superfamily. Homologues of this exported ring-forming virulence protein are found in various bacteria, most of which, but not all, are pathogens, such as $P$. aeruginosa, Yersinia pestis, uropathogenic E. coli and the insect pathogen Photorhabdus luminescens. It has been suggested that Hcp1, a type VI secretion system effector, forms channels that cross host membranes and can connect different cell compartments (Osipiuk et al., 2011). In P. aeruginosa infections, Hcpl appears to be part of a protein secretion apparatus that is required for virulence. Hcp1 was detected in pulmonary secretions of cystic fibrosis patients and Hcp1specific antibodies were found in the sera of these patients
(Mougous et al., 2006). Hcp1 and hcp2 genes from Vibrio cholera also encode homologues of hemolysin-coregulated protein (Hcp) that are co-expressed with HlyA hemolysin and, as expected, double deletion $h c p$ mutants show an avirulent phenotype (Pukatzki et al., 2006).

A collagenase encoded by CV2001, a metallopeptidase member of the thermolysin-like peptidases that shares a conserved zinc binding motif, is another protein found in the $C$. violaceum supernatant that may be involved with its infection capacity. Metalloproteinases have been described as virulence factors in several microorganisms such as Clostridium botulinum, $V$. cholerae, and $P$. aeruginosa (Beaufort et al., 2011), since they can cause tissue damage and help bacterial dissemination (Miyoshi and Shinoda, 2000). Similar to the porin family of OmpC proteins, the C. violaceum collagenase has a predicted secretion motif. Finally, three other proteins found in C. violaceum supernatant, the product of the CV1097, flagellin D, and a peroxidase, may also be involved with $C$. violaceum virulence. The CV1097 gene has sequence similarity to $\mathrm{ABC}$ transporters, which are responsible for the ATP dependent efflux of various compounds (Fukuda and Schuetz, 2012). Due to the efflux of antibiotics, their activity can decrease antibiotic susceptibility in many bacteria (Piddock, 2006). Flagellin was identified in enteropathogenic E. coli (EPEC) supernatant as its major proinflammatory component, being strongly associated with gastroenteritis caused by EPEC (Khan et al., 2008). Peroxidases are known to be involved with bacterial response to environmental oxidative stress and may be involved with evasion from the host immune system (Brito et al., 2004). Although a number of other molecules produced by C. violaceum under different growth conditions or using alternative strategies of analysis still remain to be identified, this study is the first proteomic study aimed at the identification of factors involved with $C$. violaceum pathogenicity, an aspect of the biology of this bacterium that is still poorly known. 
In the original description of the $C$. violaceum genome, several open reading frames (ORFs) related to the pathogenicity of this bacterium were identified (Vasconcelos et al., 2003) but so far, the product of only one gene (CV1918), encoding a Serratia-type hemolysin, was characterized (Brumbach et al., 2007). Herein, in addition of confirming that $C$. violaceum produces secreted proteins with hemolytic activity, we identified a family of five genes encoding homologs of outer membrane porins previously described as virulence factors in other Gram-negative bacteria, which were not identified in the initial genome annotation. We also showed that the product of one of these genes (CV3424) is found in the culture supernatant of $C$. violaceum. Together with a secreted collagenase (CV2001) and the type VI secretion system effector protein Hcp1 (CV3977), these proteins constitute wellknown virulence factors described in other pathogenic bacteria, but which we identified for the first time as possible virulence factors in $C$. violaceum. Further characterization of their roles during infection will contribute to the understanding of tissue-damage mechanisms employed by this bacterium. These studies may also highlight the pathogenicity potential of $C$. violaceum, a soil and water-borne bacterium that is able to cause infections that may be more severe than previously recognized.

This study was supported by grants from Conselho Nacional de Desenvolvimento Científico e Tecnológico (CNPq) and Coordenação de Aperfeiçoamento de Pessoal de Nível Superior (Capes). AMAN, MSC, MPB, MFH, and SMRT are recipients of $\mathrm{CNPq}$ fellowships.

\section{References}

Andrews, N.W. and Whitlow, M.B. 1989. Secretion by Trypanosoma cruzi of a hemolysin active at low pH. Mol. Biochem. Parasitol. 33, 249-256.

Beaufort, N., Corvazier, E., Hervieu, A., Choqueux, C., Dussiot, M., Louedec, L., Cady, A., de Bentzmann, S., Michel, J., and Pidard, D. 2011. The thermolysin-like metalloproteinase and virulence factor LasB from pathogenic Pseudomonas aeruginosa induces anoikis of human vascular cells. Cell. Microbiol. 13, 1149-1167.

Bernardini, M.L., Sanna, M.G., Fontaine, A., and Sansonetti, P.J. 1993. OmpC is involved in invasion of epithelial cells by Shigella flexneri. Infect. Immun. 61, 3625-3635.

Brito, C.F.A., Carvalho, C.M.B., Santos, F.R., Gazzinelli, R.T., Oliveira, S.C., Azevedo, V., and Teixeira, S.M.R. 2004. Chromobacterium violaceum genome: molecular mechanism associated with pathogenicity. Genet. Mol. Res. 3, 148-161.

Brumbach, K.C., Eason, B.D., and Anderson, L.K. 2007. The serratia-type hemolysin of Chromobacterium violaceum. FEMS Microbiol. Lett. 267, 243-250.

Chatfield, S.N., Dorman, C.J., Hayward, C., and Dougan, G. 1991. Role of ompR-dependent genes in Salmonella typhimurium virulence: mutants deficient in both OmpC and OmpF are attenuated in vivo. Infect. Immun. 59, 449-452.
Chattopadhyay, A., Kumar, V., Bhat, N., and Rao, P. 2002. Chromobacterium violaceum infection: a rare but frequently fatal disease. J. Pediatr. Surg. 37, 108-110.

Cluss, R.G., Silverman, D.A., and Stafford, T.R. 2004. Extracellular secretion of the Borrelia burgdorferi Oms 28 porin and Bgp, a glycosaminoglycan binding protein. Infect. Immun. 72, 6279-6286.

Durán, N. and Menck, C.F. 2001. Chromobacterium violaceum: a review of pharmacological and industrial perspectives. Crit. Rev. Microbiol. 27, 201-222.

Fukuda, Y. and Schuetz, J.D. 2012. ABC transporters and their role in nucleoside and nucleotide drug resistance. Biochem. Pharmacol. 83, 1073-1083.

Han, X.Y., Han, F.S., and Segal, J. 2008. Chromobacterium haemolyticum sp. nov., a strongly haemolytic species. Int. J. Syst. Evol. Microbiol. 58, 1398-1403.

Hoshino, T. 2011. Violacein and related tryptophan metabolites produced by Chromobacterium violaceum: biosynthetic mechanism and pathway for construction of violacein core. Appl. Microbiol. Biotechnol. 91, 1463-1475.

Khan, M.A., Bouzari, S., Ma, C., Rosenberger, C.M., Bergstrom, K.S.B., Gibson, D.L., Steiner, T.S., and Vallance, B.A. 2008. Flagellin-dependent and independent inflammatory responses following infection by enteropathogenic Escherichia coli and Citrobacter rodentium. Infect. Immun. 76, 1410-1422.

Lima-Bittencourt, C.I., Costa, P.S., Barbosa, F.A.R., Chartone-Souza, E., and Nascimento, A.M.A. 2011. Characterization of a Chromobacterium haemolyticum population from a natural tropical lake. Lett. Appl. Microbiol. 52, 642-650.

Miller, D.P., Blevins, W.T., Steele, D.B., and Stowers, M.D. 1988. A comparative study of virulent and avirulent strains of Chromobacterium violaceum. Can. J. Microbiol. 34, 249-255.

Miyoshi, S. and Shinoda, S. 2000. Microbial metalloproteases and pathogenesis. Microbes Infect. 2, 91-98.

Mougous, J.D., Cuff, M.E., Raunser, S., Shen, A., Zhou, M., Gifford, C.A., Goodman, A.L., Joachimiak, G., Ordoñez, C.L., Lory, S., and et al. 2006. A virulence locus of Pseudomonas aeruginosa encodes a protein secretion apparatus. Science 312, 1526-1530.

Nikaido, H. 2003. Molecular basis of bacterial outer membrane permeability revisited. Microbiol. Mol. Biol. Rev. 67, 593-656.

Osipiuk, J., Xu, X., Cui, H., Savchenko, A., Edwards, A., and Joachimiak, A. 2011. Crystal structure of secretory protein Hcp3 from Pseudomonas aeruginosa. J. Struct. Funct. Genomics 12, 21-26.

Piddock, L.J. 2006. Multidrug-resistance efflux pumps - not just for resistance. Nat. Rev. Microbiol. 4, 629-636.

Pukatzki, S., Ma, A.T., Sturtevant, D., Krastins, B., Sarracino, D., Nelson, W.C., Heidelberg, J.F., and Mekalanos, J.J. 2006. Identification of a conserved bacterial protein secretion system in Vibrio cholerae using the Dictyostelium host model system. Proc. Natl. Acad. Sci. USA 103, 1528-1533.

Rolhion, N., Barnich, N., Claret, L., and Darfeuille-Michaud, A. 2005. Strong decrease in invasive ability and outer membrane vesicle release in Crohn's disease-associated adherent-invasive Escherichia coli strain LF82 with the $y f g L$ gene deleted. J. Bacteriol. 187, 2286-2296.

Vasconcelos, A.T.R. and the Brazilian National Genome Project Consortium. 2003. Complete genome sequence of Chromobacterium violaceum reveals remarkable and exploitable bacterial adaptability. Proc. Natl. Acad. Sci. USA 100, 11660-11665. 